\title{
BMJ Open Cohort profile: the Ontario Life After Workplace Injury Study (OLAWIS)
}

\author{
Cameron Mustard (D) , ${ }^{1,2}$ Victoria Nadalin (D) , ${ }^{1}$ Nancy Carnide (D) ${ }^{1}$ \\ Emile Tompa (D) , ${ }^{1,2}$ Peter Smith (D) ${ }^{1,2}$
}

To cite: Mustard C, Nadalin V, Carnide N, et al. Cohort profile: the Ontario Life After Workplace Injury Study (OLAWIS). BMJ Open 2021;11:e048143. doi:10.1136/ bmjopen-2020-048143

- Prepublication history for this paper is available online. To view these files, please visit the journal online (http://dx.doi org/10.1136/bmjopen-2020048143).

Received 22 December 2020 Accepted 23 August 2021

Check for updates

(C) Author(s) (or their employer(s)) 2021. Re-use permitted under CC BY-NC. No commercial re-use. See rights and permissions. Published by BMJ.

${ }^{1}$ Institute for Work and Health, Toronto, Ontario, Canada ${ }^{2}$ Dalla Lana School of Public Health, University of Toronto, Toronto, Ontario, Canada

Correspondence to Professor Cameron Mustard; cmustard@iwh.on.ca

\section{ABSTRACT}

Purpose The substantial economic burden of workrelated injury and illness, borne by workers, employers and social security programmes, is primarily attributed to the durations of work disability among workers whose recovery requires a period of absence from work, with the majority of costs arising from the minority of workers with the longest duration absences. The objective of the Ontario Life After Workplace Injury Study is to describe the long-term health and labour market outcomes of workers disabled by work injury or illness after they are no longer receiving benefits or services from the work disability insurance authority.

Participants Workers disabled by a work-related injury or illness were recruited from a sample frame of disability benefit claimants with oversampling of claimants with longer benefit durations. Characteristics of workers, their employers and claimant benefits were obtained from baseline administrative data. Interviews completed at 18 months post injury (T1) and to be completed at 36 months (T2) measure return-to-work and work status; income; physical and mental health; case manager and healthcare provider interactions and employer accommodations supporting return-to-work and sociodemographic characteristics. Of eligible claimants, $40 \%$ (1132) participated in the T1 interview, with $96 \%$ consenting to participate in the T2 interview.

Findings to date Preliminary descriptive analyses of T1 data have been completed. The median age was 50 years and $56 \%$ were male. At 18 months following injury, $61 \%$ were employed by their at-injury employer, $16 \%$ had changed employment and $23 \%$ were not working. Pastyear prescription opioid use was prevalent $(34 \%)$, as was past-year cannabis use (31\%). Longer duration claimants had poorer function, recovery and health and more adverse labour market outcomes.

Future plans Multivariate analyses to identify modifiable predictors of adverse health and labour market outcomes and a follow-up survey of $96 \%$ of participants consenting to follow-up at 36 months are planned.

\section{INTRODUCTION}

The burden of work-related injury and illness among workers in the developed economies is substantial. Among working-aged adults, one of every six injuries requiring medical attention are caused by work exposures ${ }^{1}$ with approximately $35 \%$ of these work-related injuries and illnesses resulting in periods of

\section{Strengths and limitations of this study}

This longitudinal study collected information from workers disabled by a work-related injury or illness 18 months and 36 months following the beginning of an episode of work disability.

- This large, representative sample will inform understanding of the long-term consequences to health and labour force participation among an important subgroup of workers who experience long durations of work disability.

- As eligibility criteria for participation in this cohort was restricted to disability due to a work-related injury or illness, the many other health conditions that can result in work disability are not represented in this cohort.

disability and work absence. An important minority of work injury or illness results in some degree of permanent impairment. For example, in a representative sample of Canadian adults, $25 \%$ of adults with disabilities attributed the underlying impairment to an exposure at work. ${ }^{2}$

The economic burden of work-related injury and illness borne by workers, employers and social security programmes is also substantial. ${ }^{3}$ Much of this economic cost is attributed to the durations of work disability among workers whose recovery requires a period of absence from work. In addition to the economic costs attributed to compensation for lost income during the period of work absence, there is compelling evidence for long-lasting adverse impacts of work disability episodes on injured workers' subsequent labour force participation and labour market earnings. ${ }^{45}$

While the durations of work disability are relatively short for the majority of work absence episodes, for an important minority of episodes, disability durations can be long, may result in loss of employment and are responsible for the majority of work disability insurance programme expenditures. Understanding the factors that influence the duration of work disability episodes 
has been informed by research focused on four primary domains: characteristics of the injury and the worker, the nature of workplace accommodations to support workers returning to work, access to and the appropriateness of healthcare and the influence of benefit policies established by work disability insurance providers. Longitudinal cohort studies of injured workers have documented the role of injury severity, persistent pain, mental health impairments, older age and recovery expectations as determinants of long-duration disability episodes. ${ }^{6-9}$ Understanding the influence of employer accommodation practices on disability episode has been informed both by observational cohort studies and by experimental study designs involving randomised controlled trials. ${ }^{10-16}$ Quasi-experimental study designs have advanced understanding of the influence of disability insurance provider policies on the durations of work disability. ${ }^{16-19}$

The contributions of this literature have led to important reforms to workplace and disability insurer practices in many jurisdictions. However, there has been less attention focused on describing the experiences of workers disabled by a work-related injury or illness over longer follow-up periods or adequately powered comparisons between the experiences of workers' compensation claimants with long wage replacement durations compared with claimants with shorter durations. The objective of the Ontario Life After Workplace Injury Study (OLAWIS) is to describe the long-term outcomes of workers disabled by work injury or illness. The study design oversampled disability benefit recipients with longer duration disability episodes and incorporates measures obtained at baseline from administrative records with measures obtained from interviews with study subjects 18 months and 36 months following the incidence of disabling injury or illness.

In designing this study, we expected that poor health recovery outcomes at 18 months and 36 months will be more common among women, workers aged 50 years or older, workers experiencing more severe traumatic injury or non-traumatic musculoskeletal disorders and those using opioid medications. In parallel, we hypothesised that shorter durations of wage replacement benefits will be more common among workers who report early employer contact and who report an employer offer of accommodation. In terms of labour market outcomes, we expected that a return to work with the at-injury employer will be more common among workers with longer preinjury employment tenure, workers who are union members and workers with a positive perception of employment security. Poor labour market outcomes at 18 months and 36 months will be more common among workers with low educational attainment, workers who have recently immigrated to Canada and workers with high symptom scores for pain and poor mental health. Examination of these hypotheses will contribute to the international literature on the impact of health impairments secondary to traumatic injury on labour force participation and the role of workplace accommodation in enabling employment participation among workers with health impairments.

\section{COHORT DESCRIPTION}

\section{Setting}

In 2018, there were approximately 6.5 million labour force participants in Ontario, Canada. The majority of employers in Ontario (approximately 70\%) have a mandatory obligation to obtain work disability insurance coverage from the publicly administered, single-payer workers' compensation insurance authority, the Workplace Safety and Insurance Board (WSIB). Employers also have a legislated obligation to accommodate employees with health impairments, including the duty to accommodate employees who have experienced a work-related injury or illness. The WSIB administers benefits to entitled workers, covering medical care services and provides wage replacement benefits for workers whose recovery from a work-related injury or illness requires absence from work. In 2018, the WSIB administered benefits for 160000 compensation claims, of which 48000 were claims resulting in lost time from work. The WSIB also schedules employer insurance premiums that incorporate financial incentives to encourage early return-to-work practices by employers.

\section{Baseline recruitment}

Study sample recruitment was conducted between June 2019 and March 2020. WSIB administrative records were used to identify with workers who had registered a compensation claim for wage replacement benefits due to a physical injury or illness approximately 18 months prior.

To ensure adequate representation of participants with more serious and complex claims in the cohort, the OLAWIS sampling plan specified that approximately 400 participants were to be recruited in each of three compensation duration sample groups: short duration, that is, 5 days to 3 months; medium duration, that is, 3-12 months and longer duration, that is, $12+$ months. We excluded lost-time claimants with benefit durations of less than 5 days. These claimants represented approximately $30 \%$ of all lost-time claimants. The short-duration sample represented $54 \%$ of all lost-time claimants, the medium-duration sample represented $9 \%$ of all lost-time claimants and the longer duration sample represented $6 \%$ of all lost-time claimants. The rationale for recruiting three equal-sized samples of claimants, stratified by claim duration and complexity, was to obtain sufficient statistical power to identify claimant characteristics that meaningfully differ between the more frequent shortduration claimant profile and the less frequent longduration claimant profile. Survey weights are applied for analyses that focus on representing the target population of claimants with durations of 5 days or longer. A sample of 400 respondents in each group has the power to estimate statistically significant relative risks of 2.0 or greater for measures with prevalence of $10 \%-20 \%$ (a prevalence difference of $5 \%$ in one group and $10 \%$ in a second group) and can detect relative risks of $1.5 \%$ for measures with an average prevalence of $20 \%$ or greater 


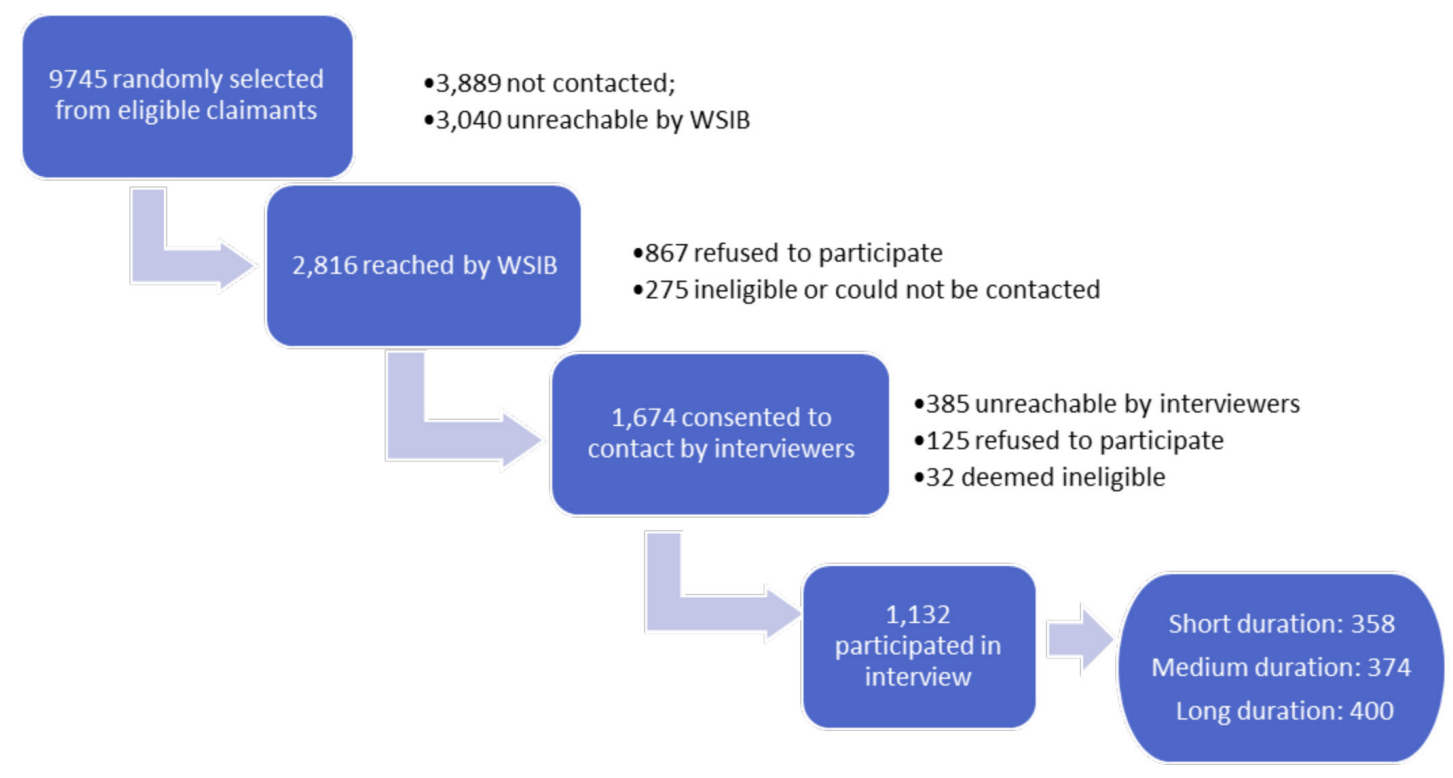

Figure 1 Participant flow diagram. WSIB, Workplace Safety and Insurance Board.

(a difference of $13 \%$ in one group and $20 \%$ in a second group).

Records for 9745 lost-time claimants were randomly selected by representatives of the WSIB to meet quota targets specified by the OLAWIS research team. WSIB representatives contacted claimants by telephone to obtain monthly quotas of claimants consenting to share their contact information with the OLAWIS research team. Lost-time claimants with a primary psychological injury, who were in the survivors programme or serious injury programme, who had a traumatic head injury resulting in communication impairment, younger than age 18 years or who could not conduct an interview in English or French were excluded.

Of the 2816 claimants contacted, a total of 1674 (59.4\%) agreed to share their contact information. Of the claimants consenting, the survey services contractor was unable to establish contact with 385 claimants, received 125 interview refusals, 32 claimants were deemed ineligible and interviews were completed with 1132 claimants $(40.1 \%$ of eligible claimants and $87.7 \%$ of eligible claimants successfully contacted). Figure 1 shows the flow of participants.

Among participants, $358(31.6 \%)$ were in the shortduration claim sample, $374(33.0 \%)$ were in the mediumduration claim sample and $400(35.3 \%)$ were in the long-duration claim sample. In this cohort of 1132 claimants, $96 \%$ consented to be recontacted for the 36-month follow-up survey and $94 \%$ gave permission to the research team to access information recorded in their WSIB administrative record.

Analyses were conducted comparing the 1132 interview participants to consenting claimants who did not complete an interview and to the randomly selected recruitment sample. No substantive differences were observed between samples based on age, gender, geographic location, industry and employer size. However, duration of benefits was slightly longer among participants versus non-participants (details available on request).

\section{Patient and public involvement}

Patients and the public were not involved in the design, conduct, reporting or dissemination plans of this research.

\section{Data collection}

Primary outcome measures and potential predictors of the primary outcomes were drawn from two sources: WSIB administrative records and an intervieweradministered questionnaire. Information available from administrative records of work disability insurance benefits was integrated with the information obtained from an interviewer-administered questionnaire. With participant's consent, information obtained from administrative records included measures of the nature of injury and injury event, benefit duration, workers' occupation and geographic location and the employer size and economic sector.

\section{Interviewer-administered questionnaire: 18 months}

Questionnaire measures were grouped in the following topic domains: 1) Return-to-work and labour market status; 2) function, recovery and measures of physical and mental health; 3) interactions between the claimant and the work disability insurance case managers; 4) interactions between the claimant and their healthcare providers; 5) and basic sociodemographic characteristics and preinjury information on occupation, industry and workplace size. Relevant measures administered in previous cohort studies of disabled workers ${ }^{12} 20$ and measures administered in the Canadian Community Health Survey ${ }^{21}$ were incorporated in the OLAWIS questionnaire when available. The interviews conducted by the survey services contractor lasted approximately $40 \mathrm{~min}$ and participants were remunerated $\$ \mathrm{C} 40$. 
Return-to-work and labour market status

Respondents were asked whether they were currently working with their preinjury employer and were asked a series of questions about interactions with the workplace where the injury occurred during the period of recovery and return to work. The questionnaire included items related to the frequency and quality of communication with the workplace, the nature of modified duties or accommodations proposed by the workplace and perceptions of the outcome of the return-to-work experience. For employed respondents not currently working with their preinjury employer, information was collected on the main reason they were not working with their preinjury employer. For respondents not currently working, information was collected on whether they had made a return-to-work attempt and their perception of the main reason they were not currently working.

\section{Function, recovery and measures of physical and mental health}

The questionnaire included a range of measures of function, recovery and health outcomes. Current intensity of pain was measured by the Chronic Pain Grade Scale and pain-related interference with normal activities was assessed. $^{22}$ Measures of self-rated health status and selfrated mental health status ${ }^{23-27}$ were administered along with the 12-item short-form health survey (SF-12 Scale) ${ }^{28}$ and the Kessler- 6 screening tool for mental disorder symptoms. ${ }^{29}$ The questionnaire included a series of items used in the Canadian Community Health Survey ${ }^{21}$ to assess perceptions of work stress, life stress and life satisfaction, sleep quality, alcohol consumption and medication use. Questions were also included on current cannabis use and if use was for therapeutic purposes.

\section{Interactions between the claimant and the work disability insurance case managers}

Respondents were asked to assess the quality of interactions with work disability insurance case managers, both in terms of interpersonal treatment and the quality of the information provided by case managers. ${ }^{1130}$

\section{Interactions between the claimant and their healthcare providers}

The questionnaire included items documenting the respondent's main healthcare provider, whether difficulty was experienced accessing healthcare services, whether the use of healthcare services was stressful and the respondent's assessment of the clarity of advice provided by healthcare providers concerning returning to work.

\section{Sociodemographic characteristics and preinjury information on occupation, industry and workplace size}

The interview collected information on claimant age, sex, immigrant status, educational attainment, family structure, union membership, preinjury occupational tasks and work hours, workplace size and industry of employment. Respondents also provided information about the amount of personal and household income in the previous 12 months and their current main income sources.

\section{Interviewer-administered questionnaire: 36 months}

Participants who agreed to be recontacted will be administered an abbreviated version of the 18-month questionnaire, retaining topic domains concerning: (1) current labour market status, (2) function, recovery and measures of physical and mental health and (3) basic sociodemographic characteristics. An extended questionnaire domain pertaining to cannabis use will be administered to participants reporting current cannabis use at the 18-month interview. The 36-month interview will be administered over the period January to December 2021.

\section{Findings to date}

Unweighted descriptive analyses completed to date are summarised in tables 1 and 2 . The median age at the time of the baseline interview (approximately 18 months after injury) was 50 years; participants in the short-duration sample had a median age of 47 years, whereas those in the long-duration sample had a median age of 51 years. Over half of the participants $(56 \%)$ were male. The most common industries were healthcare and social assistance $(15 \%)$, construction, utilities and mining (14\%), transportation and warehousing (13\%) and manufacturing $(13 \%)$, with significant differences in industry composition across claim duration groups $(\mathrm{p}=0.003)$. Approximately $40 \%$ of the sample had a household income greater than $\$ 100000$ without a significant difference in income across claim duration groups. Participants with the longest claim durations had lower education and were less likely to be presently working. They were also more likely to have suffered a head injury, to currently be receiving services from the WSIB, to be receiving healthcare for the treatment of conditions related to the work injury, to have pain symptoms and to demonstrate greater health impairment on a range of measures.

Results regarding return to work with the at-injury employer are displayed in table 3. Initially, $90 \%$ of participants returned to their at-injury employer. Males, those in the longer claim duration sample, those in smaller workplaces and those in rural areas, were less likely to return to work with their at-injury employer. Union members and participants reporting a permanent employment arrangement at the time of injury were more likely to return to work with their at-injury employer.

Eighteen months following the work injury incident, $35 \%$ of participants reported that they were no longer working for the at-injury employer (table 4). Approximately $50 \%$ of these workers chose to terminate employment and $20 \%$ reported the employer did not have work available. Approximately $14 \%$ of participants reported that the employer had fired them or terminated the employment relationship and approximately $10 \%$ of participants chose to retire.

\section{Strengths and limitations}

The OLAWIS Cohort was designed to address two important limitations in previous research examining the determinants of adverse health and labour market 
Table 1 OLAWIS Cohort, demographic and work characteristics, by sample group

\begin{tabular}{|c|c|c|c|c|c|}
\hline & $\begin{array}{l}\text { All respondents } \\
(n=1132)\end{array}$ & $\begin{array}{l}\text { Short duration } \\
(\mathrm{N}=358)\end{array}$ & $\begin{array}{l}\text { Medium duration } \\
(\mathrm{N}=374)\end{array}$ & $\begin{array}{l}\text { Long duration } \\
(n=400)\end{array}$ & $p$ value \\
\hline Age, mean (SD), median & 47.4 (12.8), 50.0 & 45.3 (13.3), 47.0 & 47.5 (12.5), 50.0 & 49.0 (12.4), 51.0 & 0.0004 \\
\hline \multicolumn{6}{|l|}{ Highest level of education, $\mathrm{n}(\%)$} \\
\hline Some high school & $89(7.9)$ & $22(6.2)$ & $25(6.7)$ & $42(10.5)$ & 0.02 \\
\hline High school completed & $248(22.0)$ & $67(18.7)$ & $91(24.5)$ & $90(22.5)$ & \\
\hline \multicolumn{6}{|l|}{ Household income, $\mathrm{n}(\%)$} \\
\hline$<\$ 40 \mathrm{k}$ & $144(14.4)$ & 45 (13.9) & $52(16.1)$ & $47(13.2)$ & 0.89 \\
\hline$\$ 40-69 \mathrm{k}$ & $235(23.4)$ & $73(22.6)$ & $66(20.4)$ & $96(27.0)$ & \\
\hline$\$ 70-99 \mathrm{k}$ & $227(22.6)$ & $76(23.5)$ & $77(23.8)$ & $74(20.8)$ & \\
\hline Healthcare and social assistance & $170(15.0)$ & $68(19.0)$ & $40(10.7)$ & $62(15.5)$ & 0.003 \\
\hline $\begin{array}{l}\text { Construction, utilities, mining, } \\
\text { agriculture, forestry }\end{array}$ & $156(13.8)$ & $42(11.7)$ & $48(12.9)$ & $66(16.5)$ & \\
\hline Transportation and warehousing & $147(13.0)$ & $36(10.1)$ & $58(15.6)$ & $53(13.3)$ & \\
\hline Manufacturing & $142(12.6)$ & $32(8.9)$ & $50(13.4)$ & $60(15.0)$ & \\
\hline $\begin{array}{l}\text { Other services (except public } \\
\text { administration) }\end{array}$ & $139(12.3)$ & $42(11.7)$ & $52(13.9)$ & $45(11.3)$ & \\
\hline Retail, wholesale trade & $93(8.2)$ & $34(9.5)$ & $35(9.4)$ & $24(6.0)$ & \\
\hline Educational services & $99(8.8)$ & $43(12.0)$ & $31(8.3)$ & $25(6.3)$ & \\
\hline $\begin{array}{l}\text { Accommodationfood services/arts/ } \\
\text { entertainment }\end{array}$ & $87(7.7)$ & $29(8.1)$ & $26(7.0)$ & $32(8.0)$ & \\
\hline
\end{tabular}

OLAWIS, Ontario Life After Workplace Injury Study.

outcomes following an episode of work disability-length of follow-up and sample size. In terms of the first, this study follows a large, representative sample of workers who experienced a disabling work-related injury or illness for a longer time period than has typically been reported in the current literature. Information provided by claimants 18 months and 36 months following a disabling work injury will inform understanding of the long-term consequences to health, function and labour force participation. In terms of the second, the recruitment of adequate numbers of study participants with the longest durations of work disability will provide sufficient statistical power to identify the modifiable and non-modifiable characteristics of claimants associated with long disability durations, not typically possible in an inception cohort.

This study is not without limitations. Although differences between participants and non-participants on observed characteristics were minor, there may be important differences in unmeasured characteristics which may have influenced participation. Further, there will plausibly be differences in labour market outcomes in the cohort that cannot be accurately accounted for by the self-reported information obtained by the intervieweradministered questionnaire. Although not available in this context, longitudinal information on workers' wage and work history from administrative sources would enhance the interpretation of differences in labour market outcomes. ${ }^{31}$ We also note that the eligibility criteria for participation in this cohort was restricted to disability due to a work-related injury or illness. The many other health conditions that can result in work disability are not represented in this cohort.

The dual objectives of this cohort, to describe the longterm health and labour market outcomes of workers disabled by work injury or illness, may have different implications for the external validity of findings from this cohort. We would be most confident that the long-term health outcomes observed in this cohort would plausibly generalise to other developed country settings. In contrast, however, the labour market outcomes observed in this cohort will, to some degree, be a function of the labour and social security protections specific to this jurisdiction. 
Table 2 OLAWIS Cohort, injury, return to work and recovery outcomes, by sample group

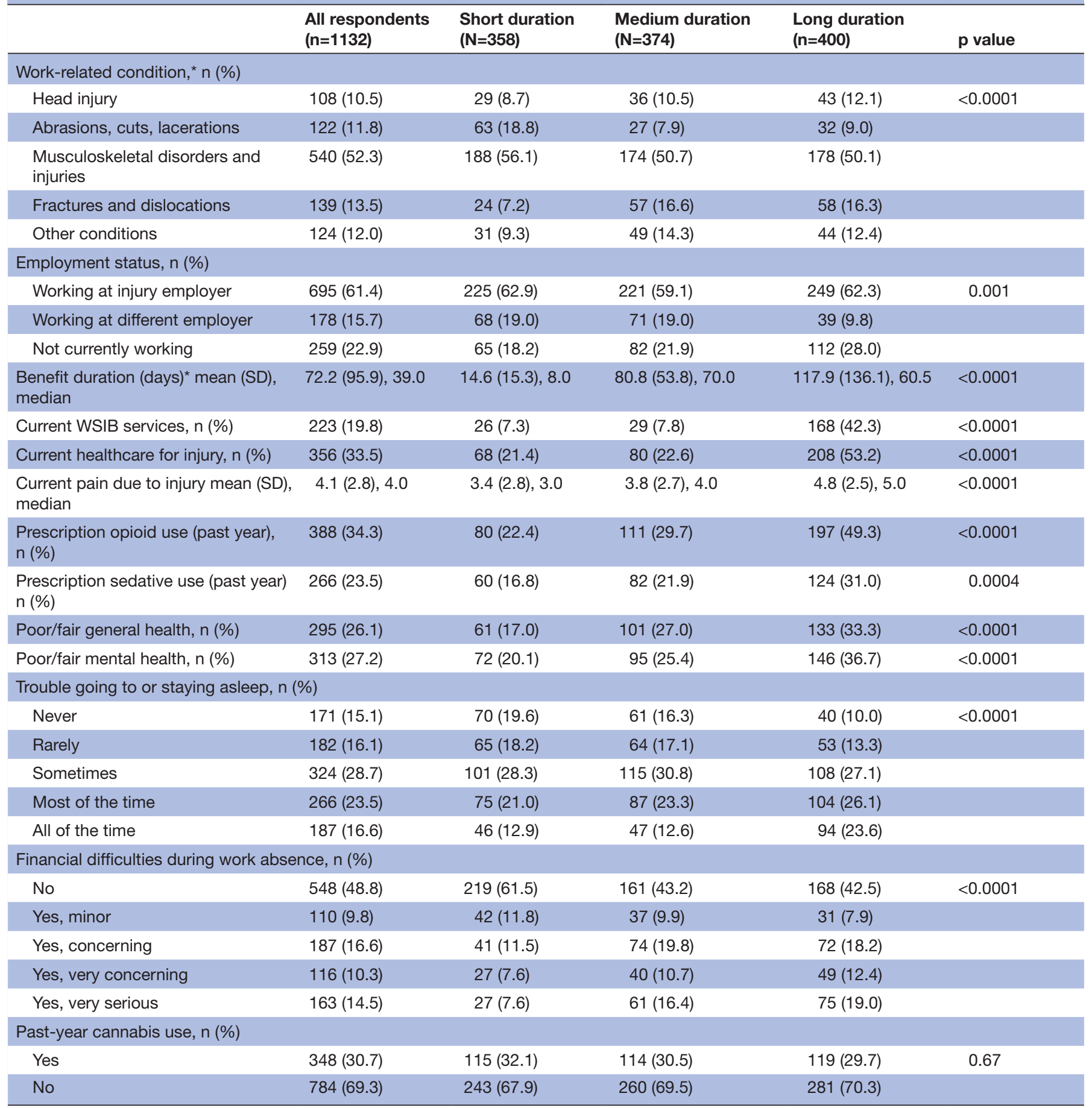

${ }^{*}$ Claimants consenting to use of WSIB administrative records.

OLAWIS, Ontario Life After Workplace Injury Study; WSIB, Workplace Safety and Insurance Board.

Although not anticipated by the OLAWIS research team, the experiences of the longitudinal cohort between the first and the second follow-up interviews will intersect with the COVID-19 public health emergency. Nationally representative surveys conducted during the emergency found that $28 \%$ of employed Canadians were concerned that they might lose their job or selfemployment income as a consequence of the emergency and $33 \%$ of respondents reported that the emergency would have a major or moderate impact on their ability to meet financial obligations. ${ }^{32}$ To respond to the acute economic effects of the COVID-19 emergency on households and on employers, the Government of Canada has rapidly implemented a range of financial relief programmes that have the potential to provide more than $\$ 140$ billion in direct support. ${ }^{33}$ We anticipate that the economic, social and health impacts of the unprecedented contraction in the Canadian labour market will 
Table 3 OLAWIS Cohort, return to work at the at-injury employer

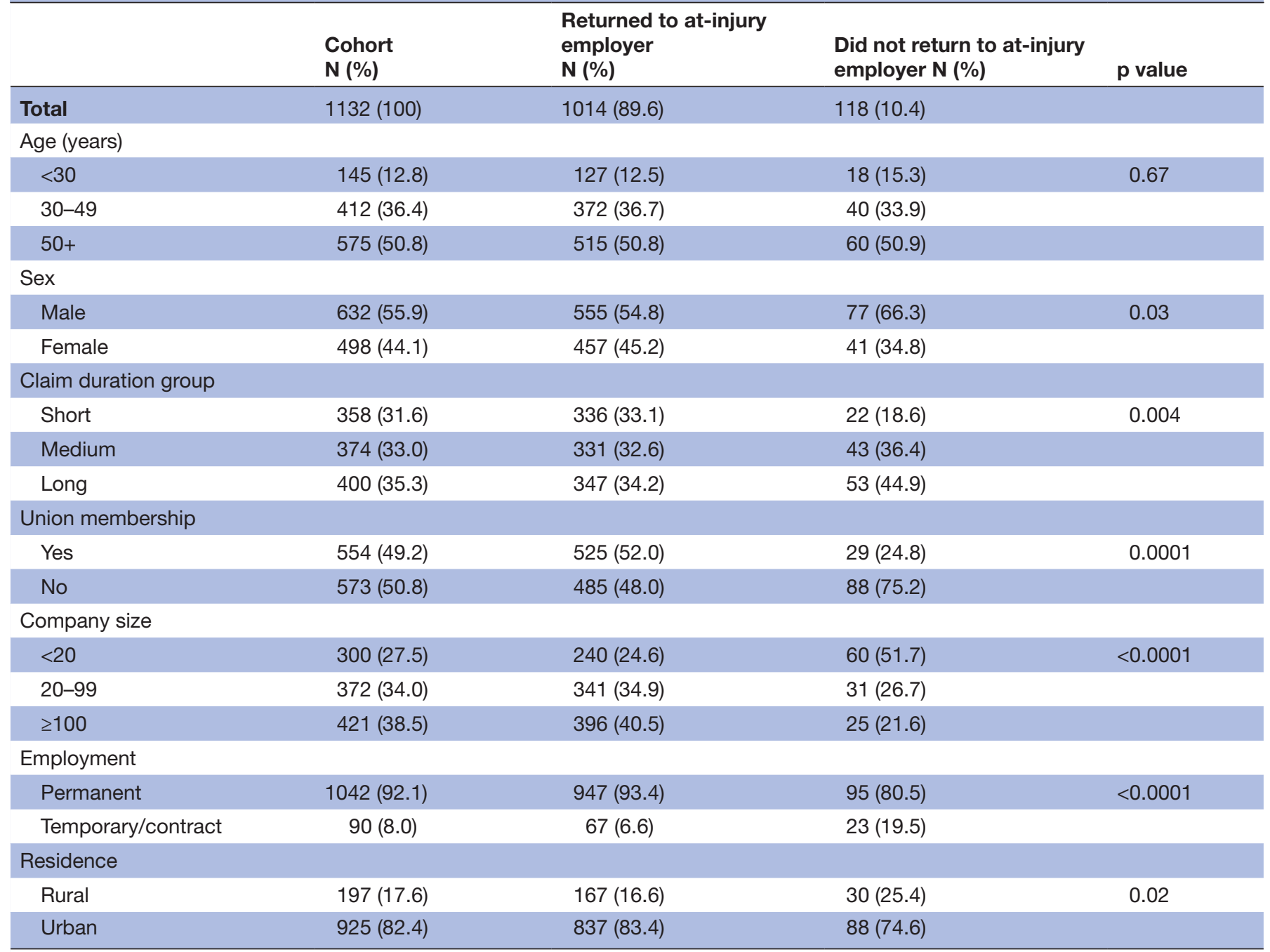

OLAWIS, Ontario Life After Workplace Injury Study.

have more substantive negative impacts on workers with health impairments.

Over the past two decades, many jurisdictions in the developed economies have achieved important

\begin{tabular}{|c|c|c|}
\hline & $\mathbf{N}$ & $\%$ \\
\hline Quit & 197 & 49.3 \\
\hline No work available & 77 & 19.3 \\
\hline Terminated/fired & 54 & 13.5 \\
\hline Retired & 35 & 8.8 \\
\hline $\begin{array}{l}\text { Misclassified (still with at-injury } \\
\text { employer) }\end{array}$ & 34 & 8.5 \\
\hline Still on WSIB benefits & 3 & 0.8 \\
\hline Total & 400 & 100.0 \\
\hline
\end{tabular}

OLAWIS, Ontario Life After Workplace Injury Study; WSIB, Workplace Safety and Insurance Board. reductions in the incidence of work-related injury and illness. ${ }^{34}$ Paralleling these achievements, progress has also been made in reducing the burden of disability among workers experiencing a work-related injury or illness. Research contributions can inform future innovations in workplace practices and disability insurance provider policies to improve the prevention and management of work disability.

Contributors VN conducted data analysis, drafted the initial manuscript and approved the final manuscript as submitted. ET, NC, PS and CM contributed to the development of the study protocol and the acquisition of research funding. They each revised the manuscript critically for important intellectual content and approved the final manuscript as submitted. CM is the principal investigator for the study. He led the conceptualisation, development and design of the study.

Funding This work was supported by Ontario Workplace Safety and Insurance Board, grant number LONG2018.

Competing interests None declared.

Patient and public involvement Patients and/or the public were not involved in the design, or conduct, or reporting, or dissemination plans of this research.

Patient consent for publication Not required. 
Ethics approval Ethics review was conducted by the Health Sciences Research Ethics Board, University of Toronto (Protocol 37525).

Provenance and peer review Not commissioned; externally peer reviewed.

Data availability statement Data are available upon reasonable request. Procedures to access data from this study are available through contacting the lead author (CM). Proposals for collaborative analyses will be considered by the study's investigator team. The study questionnaire can be provided by contacting the lead author (CM).

Open access This is an open access article distributed in accordance with the Creative Commons Attribution Non Commercial (CC BY-NC 4.0) license, which permits others to distribute, remix, adapt, build upon this work non-commercially, and license their derivative works on different terms, provided the original work is properly cited, appropriate credit is given, any changes made indicated, and the use is non-commercial. See: http://creativecommons.org/licenses/by-nc/4.0/.

\section{ORCID iDs}

Cameron Mustard http://orcid.org/0000-0002-0747-8870

Victoria Nadalin http://orcid.org/0000-0002-2337-3753

Nancy Carnide http://orcid.org/0000-0001-7892-5626

Emile Tompa http://orcid.org/0000-0002-9851-3853

Peter Smith http://orcid.org/0000-0001-8286-4563

\section{REFERENCES}

1 Chambers A, Ibrahim S, Etches J, et al. Diverging trends in the incidence of occupational and Nonoccupational injury in Ontario, 2004-2011. Am J Public Health 2015;105:338-43.

2 Morris S GF, Brisebois L, Hughes J. A demographic, employment and income profile of Canadians with disabilities aged 15 years and over, 2017. Canada Her Majesty the Queen in Right of Canada; 2018.

3 Leigh JP. Economic burden of occupational injury and illness in the United States. Milbank Q 2011;89:728-72.

4 Seabury SA, Scherer E, O'Leary P, et al. Using linked federal and state data to study the adequacy of workers' compensation benefits. Am J Ind Med 2014;57:1165-73.

5 Tompa E, Saunders R, Mustard C. Measuring the adequacy of workers' compensation benefits in Ontario: An update. Toronto Institute for Work \& Health; 2016

6 Carnide N, Franche R-L, Hogg-Johnson S, et al. Course of depressive symptoms following a workplace injury: a 12-month follow-up update. J Occup Rehabil 2016;26:204-15.

7 Black O, Keegel T, Sim MR, et al. The effect of self-efficacy on return-to-work outcomes for workers with psychological or UpperBody musculoskeletal injuries: a review of the literature. J Occup Rehabil 2018;28:16-27.

8 Hogg-Johnson S, Cole DC. Early prognostic factors for duration on temporary total benefits in the first year among workers with compensated occupational soft tissue injuries. Occup Environ Med 2003:60:244-53.

9 Cole DC, Mondloch MV, Hogg-Johnson S, et al. Listening to injured workers: how recovery expectations predict outcomes--a prospective study. CMAJ 2002;166:749-54.

10 Lane TJ, Lilley R, Hogg-Johnson S, et al. A prospective cohort study of the impact of return-to-work coordinators in getting injured workers back on the job. J Occup Rehabil 2018;28:298-306.

11 Franche R-L, Cullen K, Clarke J, et al. Workplace-Based return-towork interventions: a systematic review of the quantitative literature. J Occup Rehabil 2005:15:607-31.

12 Franche R-L, Severin CN, Hogg-Johnson S, et al. The impact of early workplace-based return-to-work strategies on work absence duration: a 6-month longitudinal study following an occupational musculoskeletal injury. J Occup Environ Med 2007;49:960-74.
13 Amick BC, Lee H, Hogg-Johnson S, et al. How do organizational policies and practices affect return to work and work role functioning following a musculoskeletal injury? J Occup Rehabil 2017;27:393-404.

14 van Vilsteren M, van Oostrom SH, de Vet HCW, et al. Workplace interventions to prevent work disability in workers on sick leave. Cochrane Database Syst Rev 2015:CD006955.

15 Vogel N, Schandelmaier S, Zumbrunn T. Return-To-Work coordination programmes for improving return to work in workers on sick leave (review). Cochrane Database Syst Rev 2017;3.

16 Viikari-Juntura E, Kausto J, Shiri R, et al. Return to work after early part-time sick leave due to musculoskeletal disorders: a randomized controlled trial. Scand J Work Environ Health 2012;38:134-43.

17 Thompson AMS, Bain D, Theriault ME. Pre-Post evaluation of an integrated return to work planning program in workers' compensation assessment clinics. J Occup Environ Med 2016;58:215-8.

18 Kausto J, Viikari-Juntura E, Virta LJ, et al. Effectiveness of new legislation on partial sickness benefit on work participation: a quasiexperiment in Finland. BMJ Open 2014:4:e006685.

19 Bethge M. Effects of graded return-to-work: a propensity-scorematched analysis. Scand J Work Environ Health 2016;42:273-9.

20 Dimitriadis C, LaMontagne AD, Lilley R, et al. Cohort profile: workers' compensation in a changing Australian labour market: the return to work (RTW) study. BMJ Open 2017;7:e016366.

21 Béland Y. Canadian community health survey--methodological overview. Health Rep 2002;13:9-21.

22 Von Korff M, Jensen MP, Karoly P. Assessing global pain severity by self-report in clinical and health services research. Spine 2000;25:3140-51.

23 Idler EL, Benyamini Y. Self-Rated health and mortality: a review of twenty-seven community studies. $J$ Health Soc Behav 1997;38:21-37.

24 Molarius A, Janson S. Self-Rated health, chronic diseases, and symptoms among middle-aged and elderly men and women. $J$ Clin Epidemiol 2002;55:364-70.

25 Singh-Manoux A, Martikainen P, Ferrie J, et al. What does self rated health measure? Results from the British Whitehall II and French Gazel cohort studies. J Epidemiol Community Health 2006;60:364-72

26 Smith PM, Glazier RH, Sibley LM. The predictors of self-rated health and the relationship between self-rated health and health service needs are similar across socioeconomic groups in Canada. $J$ Clin Epidemiol 2010;63:412-21.

27 Mawani FN, Gilmour H. Validation of self-rated mental health. Health Rep 2010;21:1-15.

28 Ware J, Kosinski M, Keller SD. A 12-Item short-form health survey: construction of scales and preliminary tests of reliability and validity. Med Care 1996;34:220-33.

29 Kessler RC, Green JG, Gruber MJ, et al. Screening for serious mental illness in the general population with the K6 screening scale: results from the WHO world mental health (WMH) survey initiative. Int $J$ Methods Psychiatr Res 2010;19 Suppl 1:4-22.

30 Orchard C, Carnide N, Smith P. How does perceived fairness in the workers' compensation claims process affect mental health following a workplace injury? J Occup Rehabil 2020;30:40-8.

31 Böckerman P, Bryson A, Ilmakunnas P. Does high involvement management improve worker wellbeing? J Econ Behav Organ 2012;84:660-80

32 Statistics Canada. Impacts of COVID-19 on Canadians: first results from crowdsourcing. Ottawa, ON Statistics Canada; 2020.

33 Office of the Parliamentary Budget Officer. Costing of Canada's COVID-19 Economic Response Plan. Ontario Government of Ontario; 2020.

34 Macpherson RA, Lane TJ, Collie A, et al. Age, sex, and the changing disability burden of compensated work-related musculoskeletal disorders in Canada and Australia. BMC Public Health 2018;18:758. 